\section{On the Thermal Behaviour of Earth-alkali Propionates and $n$.Butyrates}

\author{
P. Ferloni, M. Sanesi, and P. Franzosini \\ Centro di studio per la termodinamica ed elettrochimica \\ dei sistemi salini fusi e solidi del CNR c/o \\ Istituto di Chimica Fisica e di Elettrochimica della \\ Università, Pavia (Italy)
}

(Z. Naturforsch 31 a, 679-682 [1976] ; received May 17, 1976)

In a recent paper ${ }^{1}$ the results of a calorimetric study on the phase transitions in the alkali $\mathrm{C}_{1}-n \cdot \mathrm{C}_{4}$ alkanoates were reported. Continuing the systematic investigation on salts with organic anions, the present work deals with the enthalpies and entropies of fusion (F) and of a few solid state transitions (sstr's) in calcium, strontium and barium propionates and $n$.butyrates, a salt group for which, as far as we know, thermochemical information is completely lacking in the literature.

\section{Experimental}

The salt preparation was accomplished by addition (in slight excess) of Fluka "puriss" $\mathrm{C}_{2} \mathrm{H}_{5} \mathrm{COOH}$ or $n \cdot \mathrm{C}_{3} \mathrm{H}_{7} \mathrm{COOH}$ to a suspension of Atomergic Chemetals $5 \mathrm{~N} \mathrm{Ca}, \mathrm{Sr}$ or $\mathrm{Ba}$ carbonate in de-ionized water, and by subsequent lyophilization. When a suitable solvent could be found, a further purification was performed either by re-crystallization or by fractional precipitation. The composition of the final materials was checked through quantitative determination of calcium by EDTA titration, of strontium as $\mathrm{SrSO}_{4}$ and of barium as $\mathrm{BaSO}_{4}$. The phase transition temperatures and heat effects were determined by means of a Perkin-Elmer differential calorimeter Mod. DSC-2 : 5 to 12 samples of each salt (sealed in $\mathrm{Al}$ containers) were scanned between $110 \mathrm{~K}$ and the melt region. Auxiliary information was obtained when needed by X-ray analysis and/or by visual observation at the heating-stage polarizing microscope.

\section{Results and discussion}

Complete thermochemical data could be obtained for what concerns fusion, whereas the fact that some materials were originally amorphous, and/or exhibited a remarkable hysteresis to undergo sstr's on cooling, and/or showed metastable (m) along

Reprint requests to Prof. P. Franzosini, Istituto di Chimica Fisica e di Elettrochimica della Università, Viale T. Taramelli 16, 1-27100 Pavia (Italy). with stable (s) phases did not always allow to gain a picture of the solid state relationships.

Only phase transition temperatures, enthalpies and entropies judged as reasonably reliable are summarized in Table 1.

Concerning calcium propionate, from a solution of the lyophilized material in hot anhydrous methanol a solid was recovered (by cooling at ice temperature) which gave to analysis $\mathrm{Ca} \%=21.47$ (calcd. 21.52) and, though looking as needleshaped, proved to be completely amorphous, as well as the original liophilized one, by room temperature $\mathrm{X}$-ray diffraction patterns.

During the first heating run (see Fig. 1, upper part) all samples, after having undergone a glass transition at $T_{\mathrm{g}}=(462 \pm 4) \mathrm{K}$, exhibited large exo-
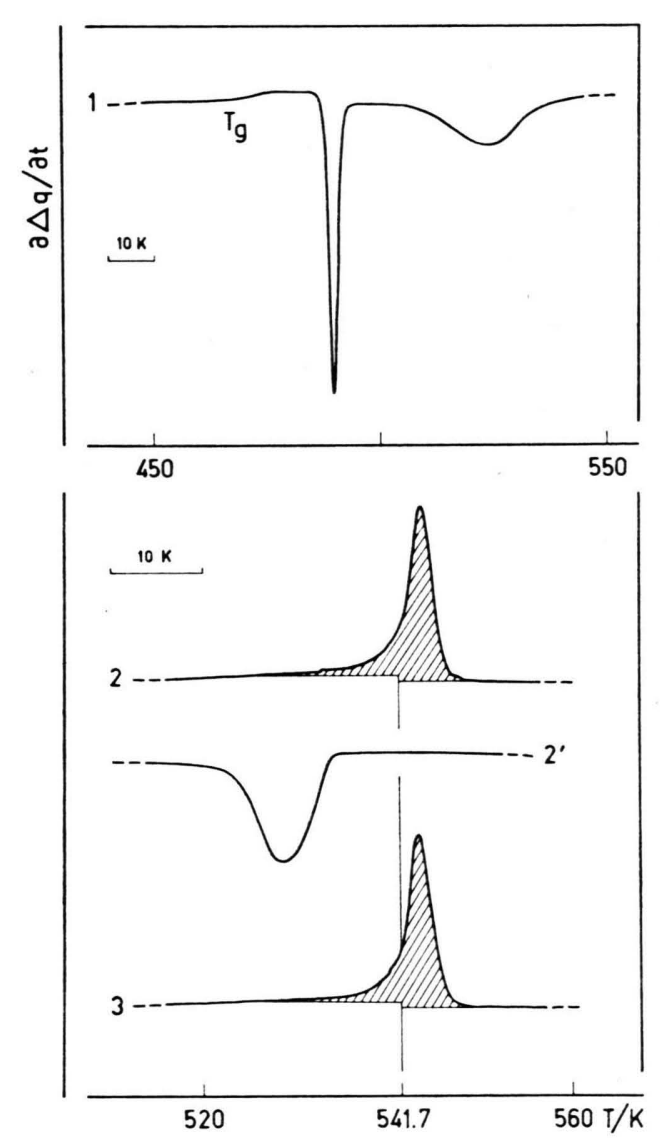

Fig. 1. Calcium propionate (sample 8 of Table 2). Curves 1, 2, 3 correspond to first, second and third heating runs; curve $2^{\prime}$ to second cooling run. All curves were recorded at $10 \mathrm{~K} \mathrm{~min}^{-1}$, using in the lower section a chart speed and a sensitivity respectively 2 and 2.5 times larger than in the upper section. To calculate the $\Delta H_{\mathrm{tr}}$ value reported in Table 2, the mean value of the satisfactorily coincident shaded areas was taken into account. 


\begin{tabular}{|c|c|c|c|c|c|}
\hline Salt & $\operatorname{tr}$ & $\frac{T_{\mathrm{tr}}}{\mathrm{K}}$ & $\frac{\Delta H_{\mathrm{tr}}}{\mathrm{kcal} \mathrm{mole}^{-1}}$ & $\frac{\Delta S_{\mathrm{tr}}}{\text { cal mole }{ }^{-1} \mathrm{~K}^{-1}}$ & $\begin{array}{l}\text { number } \\
\text { of } \\
\text { samples }\end{array}$ \\
\hline Ca propionate & $\begin{array}{l}\text { F } \\
\text { sstr }\end{array}$ & $\begin{array}{l}666 \\
541 \pm 2\end{array}$ & $\begin{array}{l}3.7_{5} \\
0.36\end{array}$ & $\begin{array}{l}5.6 \\
0.6_{7}\end{array}$ & $\begin{array}{r}10 \\
8\end{array}$ \\
\hline Sr propionate & $\mathrm{F}$ & $725 \pm 4$ & 2.5 & 3.4 & 11 \\
\hline Ba propionate & $\mathrm{F}$ & $647 \cdot 8$ & $3.3_{4}$ & $5.1_{6}$ & 11 \\
\hline Ca butyrate & $\mathrm{F}$ & $604 \cdot 3$ & $2.8_{5}$ & 4.7 & 5 \\
\hline Sr butyrate & $\mathrm{F}$ & $681_{.0}$ & $2.9_{3}$ & 4.3 & 6 \\
\hline Ba butyrate & $\begin{array}{l}\text { F } \\
\text { sstr } \\
\text { sstr } \\
\text { (metastable) }\end{array}$ & $\begin{array}{l}586 \\
500 \pm 2 \\
433 \cdot 8\end{array}$ & $\begin{array}{l}1.7_{4} \\
0.7_{9} \\
2.7^{2}\end{array}$ & $\begin{array}{l}3.0 \\
1.6 \\
6.2\end{array}$ & $\begin{array}{r}10 \\
8 \\
12\end{array}$ \\
\hline
\end{tabular}

Table 1. Thermochemical data on earthalkali propionates and $n$. butyrates.

The significant figures of each tabulated quantity depend on the degree of reproducibility in the corresponding set of experimental results (for an example, see Table 2). thermic effects in the temperature range up to $\sim 550 \mathrm{~K}$ : the corresponding transformation from the amorphous into a crystalline state was confirmed by $\mathrm{X}$-ray patterns at $\sim 600 \mathrm{~K}$. When re-cooled to room temperature it was apparent from X-ray patterns that the structure of the crystalline solid had changed: indeed, the runs subsequent to the first heating allowed to point out the existence of a sstr at $541 \mathrm{~K}$, the region around which is shown in an enlarged scale in the lower part of Figure 1 . The data on this sstr are detailed in Table 2 in order to show, at least in one case, the degree of reproducibility of DSC results.

Table 2. DSC data for sstr in calcium propionate.

\begin{tabular}{|c|c|c|c|}
\hline Sample & $\frac{\text { Sample } w t}{\mathrm{~g}}$ & $\frac{T_{\mathrm{tr}}}{\mathrm{K}}$ & $\frac{\Delta H_{\mathrm{tr}}}{\mathrm{kcal} \mathrm{mole}^{-1}}$ \\
\hline 1 & 0.006684 & 543.6 & 0.380 \\
\hline 2 & 0.007812 & 543.5 & 0.365 \\
\hline 3 & 0.003533 & 539.1 & 0.364 \\
\hline 4 & 0.004519 & 540.6 & 0.362 \\
\hline 5 & 0.002693 & 538.9 & 0.372 \\
\hline 6 & 0.004953 & 542.3 & 0.351 \\
\hline 7 & 0.003199 & 541.4 & 0.359 \\
\hline 8 & 0.008059 & 541.7 & 0.361 \\
\hline
\end{tabular}

Mean values: $T_{\mathrm{tr}}=541.4 \pm 1.4 \mathrm{~K}$ (reported in Table 1 as $541 \pm 2 \mathrm{~K}$ ) ; $\Delta H_{\mathrm{tr}}=0.364 \pm 0.006 \mathrm{kcal} \mathrm{mole}^{-1}$ (reported in Table 1 as $\left.0.36 \mathrm{kcal} \mathrm{mole}^{-1}\right)$. - Operational conditions: scan speed: 5 or $10 \mathrm{~K} \mathrm{~min}^{-1}$; sensitivity range and chart speed: as required by sample weight.

To complete information on $\left(\mathrm{C}_{2} \mathrm{H}_{5} \mathrm{COO}\right)_{2} \mathrm{Ca}$ it must be also mentioned that in a number of DSC traces more or less evident endothermic deflections were observed at approximately $360 \mathrm{~K}$, thus sug. gesting the possible existence of a second sstr at this temperature. No other transition could be put into evidence down to $110 \mathrm{~K}$.

The original lyophilized strontium and barium propionates as well as specimens obtained by frac- tional precipitation with iso- $\mathrm{PrOH}$ from concd. solutions in $\mathrm{C}_{2} \mathrm{H}_{5} \mathrm{COOH}$ were employed. The crystalline state of the starting $\mathrm{Sr}$ salt was checked through $\mathrm{X}$-ray diffractograms, whereas in the case of $\mathrm{Ba}$ propionate crystallization occurred only at $T>$ $450 \mathrm{~K}$, as proved by the heat emissions observed in this region during the first heating run of each sample. In spite of the fact that some thermograms might suggest the existence of sstr's in both salts, the difficulties pointed out at the beginning of this section allowed to get reliable thermochemical data only on fusion.

The same happened also for calcium and strontium $n \cdot$ butyrates, the former of which was examined mainly as material recovered by cooling a hot solution of the lyophilized salt in $\mathrm{MeOH}-\mathrm{EtOH}$ (1:1 by vol.), whereas the latter could not be further purified since it seemed to suffer from any manipulation.

Barium $n \cdot$ butyrate prepared according to the Experimental section was re-crystallized from $\mathrm{EtOH}-$ $\mathrm{H}_{2} \mathrm{O}$ (8: 1 by vol.) and gave to analysis $\mathrm{Ba} \% 44.01$ (calcd. 44.08). A specimen obtained using Erba "standard for gas chromatography" $n \cdot$ butyric acid was also employed: anyway, DSC analysis did not put into evidence any significant difference among samples of different origin, either re-crystallized or not further handled after lyophilization.

The thermal behaviour of this salt exhibits peculiarities a comprehensive picture of which is given in Fig. 2 through seven thermograms covering the temperature range between $\sim 400$ and $\sim 600 \mathrm{~K}$, and taken on the same sample in the same operational conditions. A reasonable explanation of the experimental facts may be given on the assumption of monotropy in barium $n \cdot$ butyrate, complicated by enantiotropy both of the $(\mathbf{m})$ and of the $(\mathbf{s})$ forms, and by possible formation of glass-like phases from the melt.

It appears likely that the original material is present at room temperature in a $\gamma(\mathbf{m})$-phase, which 


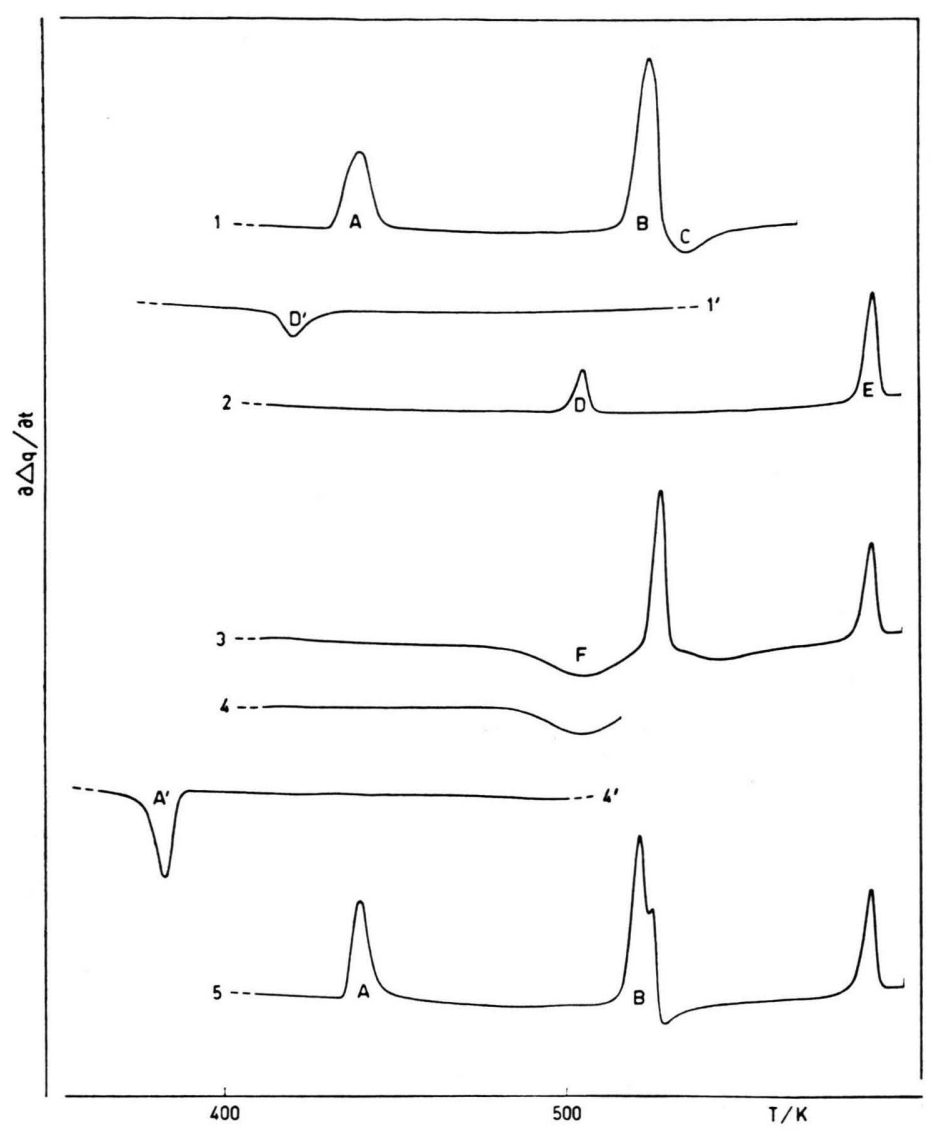

Fig. 2. Barium n. butyrate. Curve 1, first heating run (stopped at $570 \mathrm{~K}$ ). Curve 1', first cooling run. Curve 2, second heating run. The second cooling trace (not drawn) shows between $T_{\mathrm{E}}$ and $360 \mathrm{~K}$ no heat effect attributable to any definite phase transition. Curve 3, third heating run (after rest at room temperature). Curve 4, fourth heating run (stopped at $516 \mathrm{~K}$ ). Curve $4^{\prime}$, fourth cooling run: the large exothermic effect $\mathbf{A}^{\prime}$ has an area close to A. Curve 5, fifth heating run. - An unusually high scan speed, i.e., $20 \mathrm{~K} \mathrm{~min}^{-1}$ was employed in order to avoid thermal decomposition due to prolonged stays in the higher temperature range of a sample which was to be submitted to several runs up to $600 \mathrm{~K}$. Lower scan speeds (and shorter runs, similar to those shown in the lower part of Fig. 1) were on the contrary employed to draw the quantitative information reported in Table 1.

undergoes at $T_{\mathrm{A}}=433.8 \mathrm{~K}$ (see Fig. 2 and Table 1) a sstr into the $\beta(\mathbf{m})$-phase. The latter may exist up to $T_{\mathrm{B}} \sim 520 \mathrm{~K}$, a temperature at which the solid melts (or undergoes a new sstr and then immediately melts: see below). The exothermic effect $\mathbf{C}$ suggests that by increasing the temperature the melt re-crystallizes into the $\alpha(\mathbf{s})$-phase which in turn remelts at $T_{\mathrm{E}}=586 \mathrm{~K}^{*}$. This point of view is supported by visual observation and $\mathrm{X}$-ray analysis. The heating stage polarizing microscope allowed to clearly observe melting followed by re-crystallization in the temperature range where the thermal effects $\mathbf{B}$ and $\mathbf{C}$ occur, whereas X-ray patterns proved that the same sample existed in three different crystalline phases at $\sim 300, \sim 460$ and $\sim 540 \mathrm{~K}$.

Let us now first cool the solid [ $\alpha(\mathrm{s})$-phase] obtained by spontaneous re-crystallization of the $(\mathbf{m})$ melt: peak $\mathbf{D}^{\prime}$ of curve $\mathbf{1}^{\prime}$ indicates a sstr to the $\beta$ (s)-phase, whereas the reverse transition is ob-

\footnotetext{
* As for similar sequences of melting, solidifying and remelting at a higher temperature see, e.g., A. Findlay, The Phase Rule and its Applications, Dover Publications Inc., 9th Ed., 1951, p. 41.
}

served as peak $\mathbf{D}$ of curve 2. Should on the contrary the stable liquid obtained by re-melting at $T_{\mathrm{E}}$ be cooled down to room temperature, a glass-like phase is formed ** which may be converted with heat loss (see the exothermic effects $\mathbf{F}$ of curves 3 and 4 ) into a crystalline solid, which ought to be the $\beta(\mathbf{m})$ phase if the Ostwald principle of successive transformations is obeyed. This attribution is confirmed by curves $4^{\prime}$ and 5 where the transition from the $\beta(\mathbf{m})$ - to the $\gamma(\mathbf{m})$-phase and its reverse are clearly shown by the peaks $\mathbf{A}^{\prime}$ and $\mathbf{A}$, respectively.

Still worthy of a comment seem the features of peak $\mathbf{B}$ in the directly comparable curves $\mathbf{1}$ and $\mathbf{5}$, in as much as the peak shape does suggest the existence of a single effect in curve $\mathbf{1}$ and of two distinct (though very close to each other) effects in curve

\footnotetext{
* This is true when, as in the case of Fig. 2, a high scan speed is employed. By low cooling rates (e.g., $2.5 \mathrm{~K}$ $\min ^{-1}$ ) the melt is able to crystallize, though at a temperature sufficiently low to directly originate the $\beta(\mathbf{m})$-phase, which by further cooling undergoes the sstr into the $\gamma(\mathbf{m})$-phase. Therefore, the next heating thermogram will obviously look like curve $\mathbf{5}$ and not like curve 3 of Figure 2.
} 
$5^{* * *}$. This tendency to splitting, more or less evident in all barium $n$. butyrate samples submitted to DSC analysis, might be due to a $\beta(\mathbf{m})-\alpha(\mathbf{m})$ sstr, immediately followed by the metastable melting. However, owing to the closeness of the temperatures at which the involved phenomena would occur, the question remains open.

In conclusion, the phase relations in barium $n$-butyrate might be outlined as in the following scheme:

$$
\begin{aligned}
\gamma(\mathbf{m}) \rightleftarrows \beta(\mathbf{m}) \rightleftarrows \alpha(\mathbf{m})(?) & \rightarrow \operatorname{liquid}(\mathbf{m}) \\
& \rightleftarrows \underset{\downarrow}{\downarrow}(\mathbf{s}) \quad \alpha(\mathbf{s}) \rightarrow \operatorname{liquid}(\mathbf{s}) .
\end{aligned}
$$

As a final remark it may be said that poor stability at high temperature of magnesium propionate and $n$ 'butyrate did not allow to get satisfactory. $\Delta H$ data on these salts, although their melting points could be determined as respectively 577 and $567 \mathrm{~K}$

*** The difference in shape may be justified by the fact (frequently observed in salts with organic anion; see also, e.g., peak $\mathbf{A}$ in curve $\mathbf{1}$ and 5) that peaks taken on solids coming from previously melted samples are sharper than those taken on the original crystalline powders.

1 P. Ferloni, M. Sanesi, and P. Franzosini, Z. Naturforsch. 30 a, 1447 [1975]. (previous data by Pochtakova ${ }^{2}: 577$ and $575 \mathrm{~K}$ ). The present and Table $1 T_{\mathrm{F}}$ 's point to the existence of a parabolic dependence between the melting points of Group II a $n$-butyrates and those of the corresponding propionates: this noteworthy correlation is shown in Figure 3.

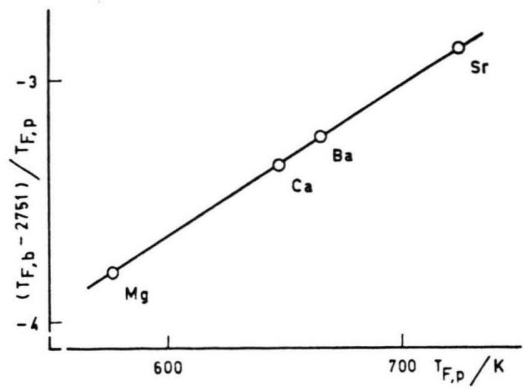

Fig. 3. Parabolic correlation between melting points of Group II a $n$. butyrates $\left(T_{\mathrm{F}, \mathrm{b}}\right)$ and propionates $\left(T_{\mathrm{F}, \mathrm{p}}\right)$.

\section{Acknowledgements}

The authors are indebted to the firm Farmabios S.p.A., Gropello C., for having kindly put at dis. posal a lyophilizing device and to Dr. G. Spinolo for his help in recording X-ray diffractograms.

2 E. I. Pochtakova, Zh. Obshch. Khim. 44, 241 [1974].

\section{BERICHTIGUNG}

J. Ramette and H. W. Drawin, Structure of Stark Broadened $\mathrm{H}_{\beta}$ Lines at Low Electron Densities, Z. Naturforsch. 31 a, $401-407$ [1976].

In the introduction of our paper we mentioned that the ion dynamical calculations of Brissaud et al. revealed an effect which is just opposite to the observations of Burgess and Cairns and of the calculations of Lee and of Barnard et al. We have been informed by Dr. Brissaud that in the quoted Ensta-report two curves have inadvertantly been inverted, thus leading to a wrong interpretation. Their calculations yield in the contrary an increase of the valley intensity when ion dynamics in included. Their published paper (J. Physics, Bd. 1976) will contain the corrected figures. 